\title{
Herança familiar na política: retrato dos limites da democracia no Brasil contemporâneo
}

\author{
Maria Cristina de Queiroz Nobre \\ Universidade Estadual do Ceará (UECE)
}

\section{Herança familiar na política: retrato dos limites da democracia no Brasil contemporâneo}

Resumo: O artigo traz reflexão teórica sobre a herança familiar na política influindo nos resultados eleitorais ainda hoje, resultado de simbiose que envolve cultura do favor, marketing político e poder econômico. Condição que sugere atualização de nossas raízes coloniais patrimonialistas e registro do inconcluso processo de modernização burguesa. O objetivo da reflexão é contribuir com pistas para se compreender a crise institucional e política que provocou a perda do mandato presidencial de Dilma Rousseff em 2016 através de golpe parlamentar, midiático e jurídico. A análise pauta-se em estudo bibliográfico no contexto de pesquisa particular sobre clãs políticos familiares do Ceará. Ao considerar outros estudos sobre o Brasil, pôde-se constatar a abrangência da influência familiar em diferentes esferas do poder político. Nesses termos, conclui-se sobre a frágil democracia brasileira que é acentuada por novo ciclo neoliberal e perspectivas de perdas de direitos sociais e trabalhistas.

Palavras-chave: Brasil. Democracia. Eleições. Herança Familiar. Crise.

\section{Political Family Clans: Portrait of the limits of democracy in contemporary Brazil}

Abstract: This article presents theoretical reflections on the influence of political family clans in electoral results until today, which is the result of a symbiosis that involves the culture of favor, political marketing and economic power. This condition suggests a revision of our colonial roots and a register of the incomplete nature of the bourgeois modernization process. The objective of the reflection is to help understand the institutional and political crisis that provoked the loss of the presidential mandate of Dilma Rousseff in 2016 through a parliamentary, media and legal coup. The analysis is based on a bibliographic study in the context of a study about political family clans in the state of Ceará. By considering other studies about Brazil, the scope of family influence in various spheres of public power can be seen. In these terms, it concludes by recognizing the fragility of Brazilian democracy, which is accentuated by a new neoliberal cycle that threatens to reduce social and labor rights.

Keywords: Brazil. Democracy. Elections. Family inheritance. Crisis. 


\section{Introdução}

No Brasil a herança familiar é fundante da política, definindo a composição do poder governamental e parlamentar em suas várias instâncias. Situação exemplar, dentre tantas, é o longínquo domínio da família Sarney no Maranhão que perdurou por 50 (cinquenta) anos. Há situações em que uma mesma família tem passagem na política desde o Brasil Colonial ou no Império e mantém representações ainda hoje na Câmara de Deputados e/ou Senado (MEDEIROS, 2016).

Se essa característica da política brasileira vem de longe em setores mais conservadores, na atualidade é extensiva a partidos progressistas. No Acre o PT tem estado à frente do governo em quatro mandatos sob a liderança dos irmãos Jorge Viana (eleito em 1998 e 2002) e Tião Viana (2010 e 2014), enquanto os dois também se revezaram no Senado Federal. No Ceará os irmãos Ciro e Cid Ferreira Gomes (PDT) marcaram presença no comando do governo estadual: o primeiro com um mandato (1990-1994) e o segundo no período de 2007 até 2014. Os dois tiveram também passagem pelo legislativo estadual, assim como o terceiro irmão Ivo. A família tem longa tradição em Sobral, onde Cid foi duas vezes prefeito (1997-2003), o pai Euclides governou de 19771983 e o bisavô foi o primeiro intendente no período republicano. As eleições de 2016 mantiveram o comando municipal de Sobral diretamente com o clã em função da vitória de Ivo Gomes (2017-...), enquanto os outros três mandatos do intervalo estiveram com aliados próximos.

O pertencimento a famílias com tradição na política viabiliza o ingresso nas estruturas de poder político por acessar o capital político construído como o negócio da família. Há que se questionar essa prática, a despeito da tradição e do perfil ideológico do grupo familiar e/ou suas lideranças, isto porque se perde o princípio da igualdade de condições para outros sujeitos postularem mandatos no parlamento e no executivo e expressarem outros interesses ou compromissos mais amplos.

A força da herança familiar persistindo nos processos eleitorais provoca discussão sobre o caráter e os limites da democracia brasileira, reflexão necessária em meio ao cenário de crise política e institucional em curso desde os primeiros episódios que envolveram a perda de mandato da Presidenta Dilma Rousseff. O golpe à democracia foi deflagrado pela mídia e por mobilizações de ruas organizadas por lideranças e grupos conservadores, concretizado por processo duvidoso no âmbito parlamentar e consubstanciado pela omissão do judiciário frente às ilegalidades do impeachment.

O cenário da crise expôs as fraturas do Brasil com a intensa polarização entre as classes sociais; tornou nítido o caráter patrimonialista de mandatos parlamentares e a submissão da pauta do legislativo a segmentos do capital; mostrou o desconhecimento da sociedade brasileira quanto à composição do parlamento. No geral, essa crise revela os limites da democracia e o inconcluso processo de revolução burguesa no país (FERNANDES, 2006), ao tempo em que tem permitido novo ciclo de contrarreforma neoliberal com fortes impactos nos direitos sociais e trabalhistas.

No âmbito desse artigo, e sem a pretensão de esgotar elementos dos processos eleitorais, pretende-se discutir a dimensão que assume a herança familiar na política brasileira e gerar reflexão teórica sobre a condição histórica que permite a permanência dessa realidade, para além de limites que a democracia encerra nas sociedades capitalistas. A discussão proposta pauta-se em pesquisa bibliográfica sobre a política brasileira; levantamentos sobre a composição do Parlamento Brasileiro realizados pela ONG Transparência Brasil; estudo bibliográfico; e observações de campo de pesquisa particular sobre perfil de deputados e prefeitos que pertencem a clãs políticos do Ceará.

Neste último caso, trata-se de pesquisa em andamento e que envolve conjunto de dados eleitorais sobre os poderes legislativo (estadual e federal) e executivo municipal. Ademais, a pesquisa tem realizado amplo levantamento de dados históricos e bibliográficos sobre 15 (quinze) clãs políticos já identificados e com significativa ascendência no poder local. A preocupação é conhecer a abrangência do poder eleitoral desses clãs, as condições da continuidade no poder, o perfil das principais lideranças, dentre outras informações relevantes. A pesquisa conta com apoio institucional do Conselho Nacional de Desenvolvimento Científico e Tecnológico (CNPq) e da Universidade Estadual do Ceará (UECE).

\section{Política na sociedade contemporânea: atualização e reconfiguração das práticas tradicionais}

O exercício da política em uma sociedade capitalista tem como determinação primeira as necessidades do capital e sua ação no conjunto da vida social em termos de dominação e hegemonia. Dessa forma, as disputas entre as classes sociais realizam-se no cotidiano como contestações que vão até certo nível, tensionando o poder do capital e das classes dominantes, mas sem provocar fissuras significativas no processo de acumulação e no exercício do poder político. 
A consciência do limite estrutural da política na sociedade capitalista não significa minimizar a importância da democracia e das liberdades conquistadas com a luta social. Ao contrário, são condições necessárias na construção de outra sociedade que possibilite a emancipação humana. Da mesma forma, a própria organização dos interesses do trabalho tendo em vista sua liberação do processo de acumulação capitalista implica a permanente luta para ampliar a liberdade e viabilizar nova hegemonia.

Nas condições contemporâneas, a política também está limitada pelas novas necessidades do capital no contexto da globalização, requerendo maior flexibilidade dos seus diversos processos, redução dos custos com o trabalho e imposição de novo consenso ideológico voltado para a centralidade do mercado e do indivíduo como sujeito de consumo. É um novo projeto burguês que põe em xeque os ideais iluministas e atribui à democracia um caráter minimalista e restrito ao campo representativo.

Nesses termos, as eleições sofrem constrangimentos legais e políticos que tornam as disputas eleitorais desiguais entre partidos políticos e candidatos, na medida em que são marcadas por forte controle do poder econômico e estão assentadas em consenso produzido pela mídia e, especialmente, pelo marketing político. A essa desigualdade se acresce o capital político construído por famílias que formam verdadeiros clãs políticos e cujo poder decorre da importância econômica que tem em suas regiões e o longínquo controle das máquinas administrativas, em geral resultante de formas tradicionais de fazer política: clientelismo e compra de votos, influência direta e coercitiva sobre o eleitor, personalismo.

Na política contemporânea os ritos eleitorais estão condicionados pela força econômica e midiática do candidato em associação às práticas tradicionais de fazer política, além do pertencimento a clãs

\section{tradicionais na política local}

$$
\text { ou aliança com esses. Tudo }
$$

\section{isto corrobora para fragilizar}

\section{os partidos políticos enquanto} espaços de construção

$$
\text { coletiva de projetos }
$$

societários, ao tempo em que

fortalece práticas do

fisiologismo.

A realização desses termos da política tradicional está relacionada à força do poder local que nunca perdeu importância na dinâmica política brasileira. Isto ocorreu ainda que esse poder tenha se transmutado enquanto o Estado nacional se consolidava com a centralização do poder político-burocrático. A esfera do poder local é fundamental para viabilizar e sustentar a ação de certos grupos na política nacional pela necessária mediação com as sociedades locais, o lugar do voto. Por sua vez, as práticas patrimonialistas e clientelistas, que historicamente permeiam o Estado e a sociedade, continuam a fortalecer grupos políticos locais, particularmente em regiões e municípios pobres onde o Estado é o grande gerador da renda municipal e principal fonte de emprego.

Na política contemporânea os ritos eleitorais estão condicionados pela força econômica e midiática do candidato em associação às práticas tradicionais de fazer política, além do pertencimento a clãs tradicionais na política local ou aliança com esses. Tudo isto corrobora para fragilizar os partidos políticos enquanto espaços de construção coletiva de projetos societários, ao tempo em que fortalece práticas do fisiologismo. Nesses termos, as alianças entre políticos e entre partidos tornam-se voláteis e com superficiais bases ideológicas, sugerindo uma relação movida por interesses imediatos, para além de afinidades no campo das ideias e de visões de mundo.

Não por acaso, o episódio que envolve a aceitabilidade do processo de impeachment da presidenta Dilma Rousseff pela Câmara dos Deputados foi marcado por certa incerteza sobre o resultado durante os dias que o antecederam. Isto porque os deputados foram intensamente assediados tanto por lideranças do governo como da oposição, supondo-se que esteve em jogo a barganha por cargos no executivo, apoios nas eleições municipais de $2016 \mathrm{e}$ mesmo os ganhos materiais imediatos. Em outros ter-

mos, a dinâmica política que se projetou esteve muito mais relacionada ao físiologismo do que pautada em convicções sobre o suposto crime de responsabilidade da presidenta. As forças governistas não foram vencidas nos argumentos, mas estavam incapazes de satisfazer a ganância política e material de muitos que há bem pouco tempo formavam sua base de apoio parlamentar. Nesse quadro complexo, representações políticas do grande capital submeteram o direito e o parlamento ao seu projeto conservador e antidemocrático que requeria a suspensão do ciclo governamental petista. 
A política de troca de favores acaba por se naturalizar e ser assumida como processo inerente a nossa sociedade. Naturalizam-se ações pontuais de ajuda da liderança política a eleitores fiéis ou a outros cujos votos podem ser conquistados no próximo pleito. São ações como o envio de ambulância para deslocamento de doentes, garantir furar a fila para atendimento mais rápido em hospitais e em postos de saúde, o recebimento de remédios, etc. Pode haver também favor mais duradouro como garantia de emprego na burocracia estatal em cargos de confiança e através da terceirização que permite ao gestor e seus aliados a indicação dos futuros contratados da empresa licitada. Essa prática do favor se realiza também entre políticos e agentes do capital por meio de acordos espúrios nos processos de licitação dos contratos governamentais; com beneficiamento de emendas parlamentares e legislações específicas para determinadores setores, dentre outros tantos mecanismos. Em contrapartida, obtêm-se recursos financeiros para as próximas campanhas e até benefícios diretos aos candidatos.

Assim, a despeito dos avanços democráticos e de fortalecimento das instituições que vinham ocorrendo desde o fim da ditadura civil-militar em 1989, a política brasileira continua envolta em relações de trocas. Estas são movidas mais por alianças estratégicas de partidos e personagens visando à manutenção de seus interesses imediatos ou aquisição do poder, seja no interior de partidos ou de grupos políticos e familiares. Relativizamse os compromissos de campanhas, em geral aquelas com apelo popular. Os projetos e interesses políticos do capital se sobrepõem às origens sociais e corporativas de muitos candidatos a despeito dos prejuízos que possam trazer às suas bases eleitorais. Aprisionam-se os mandatos parlamentares ou o poder executivo pela própria dependência de grandes recursos para viabilizar a conquista eleitoral.

\section{Raízes históricas da herança familiar na política brasileira}

A herança familiar na política está relacionada à forma particular da colonização dessas terras a partir da distribuição de grandes latifúndios pela Coroa Portuguesa, permitindo a ocupação inicial do país motivada pela produção dos bens primários de interesse do mercado europeu. Esse modelo da plantation espalhou-se pelo Nordeste e foi se estendendo por outras regiões, tendo na estrutura dos engenhos o centro da vida social e política (FREIRE, 2014). No comando estava o coronel que exercia seu poder para além da propriedade, assumindo a administração das vilas e pequenas cidades. Enfim, o poder local era compartilhando com a Coroa Portuguesa (FAORO, 2001) e fortalecia as famílias que estavam na base da economia latifundiária.

A manutenção dessa força familiar nos momentos eleitorais e no conjunto da vida política contemporânea evidencia os limites da própria revolução burguesa no Brasil (FERNANDES, 2006). De modo geral, a construção do Brasil como nação, sobretudo a partir da República e com a liderança de emergentes setores burgueses urbanos, submeteu a política com vistas não apenas a barrar as forças populares autônomas e seus projetos emancipatórios, ademais empreendeu esforços para tolher suas reivindicações de acesso à cidadania burguesa. Como resultado, a nação brasileira fundou-se a partir da aceitação e naturalização da desigualdade de seu povo, mas também se pautou no privilégio de origem familiar como mecanismo de acesso ao poder.

A revolução burguesa no Brasil, ao travar as perspectivas de modernização política e de instituição da cidadania, realizou-se mantendo e reconfigurando o controle da máquina administrativa, nos termos conservadores e oligárquicos. Isto implicou em práticas do favor e do empreguismo, correlatas ao compadrio colonial; gerou a debilidade histórica dos partidos e permitiu projetos políticos descolados das grandes necessidades nacionais; provocou a artificialidade da disputa eleitoral já que marcada pela significativa influência do personalismo, da tradição familiar, do poder econômico e, mais recentemente, do marketing eleitoral como elementos decisivos para as vitórias eleitorais.

Com a naturalização da política de troca de favores e sua visibilidade maior na esfera local, é exatamente nesse âmbito do exercício da política que se atribui grande responsabilidade pela dificuldade na realização de nossa democracia. Isto porque as alianças, mesmo com poderio econômico, não podem prescindir do controle da política neste espaço de disputas de votos. Aqui a tradição familiar e o personalismo em vínculo direto com as bases eleitorais são fundamentais. O status político é mantido ao se utilizar mais largamente de moedas de trocas e influência pessoal, o que acaba por travar a dinâmica democrática.

No desenvolvimento histórico da sociedade brasileira foi imprescindível o poder local enquanto base de legitimação dos dirigentes estaduais e federais. Na atualidade, mantém-se necessária a relação desses dirigentes com as lideranças (políticos com mandatos e líderes comunitários), com elas estabelecendo compromissos e alianças políticas que assegurem a ascensão e a continuidade no poder de determinados grupos e/ou partidos políticos, para além da artificialidade de discursos eleitorais voltados aos eleitores.

A mediação entre Estado político e sociedade civil no Brasil se ampara fortemente no clientelismo, " [...] na troca de favores políticos por benefícios econômicos, não importa em que escala.” (MARTINS, 1994, p. 
29). Na medida em que se expande a organização do Estado nacional, a trama do poder absorve na rede de dependência estatal as elites políticas que daí extraem força e condição de domínio. Por sua vez, amplos setores da sociedade ficam envoltos na trama do poder porque precisam do Estado e da necessária intermediação política como fonte de atendimento as suas necessidades.

O caráter conservador do poder político no Brasil implica, portanto, que as elites dominantes operem mecanismos de favores para consolidarem sua condição de domínio, abusando fartamente do recurso público, ademais do estabelecimento de seus próprios privilégios. No que se refere a setores da sociedade, há certa legitimação da cultura da apropriação de bens públicos pelo privado, como forma necessária do atendimento de necessidades que, não respondidas na forma de direitos sociais, são alcançadas por meio daquela intermediação política.

O clientelismo, presente desde a formação do Estado nacional, se cristaliza nas relações sociais contemporâneas, ampliando sua rede de alcance e fragilizando o nosso débil sistema representativo. Nestes termos, o poder político se distancia de interesses e necessidades da maioria e torna-se instrumento em benefícios de poucos com acesso ao poder estatal e parlamentar. O clientelismo também contribui para reproduzir instituições e práticas de domínio político de antigas e novas elites. Assim, mesmo com a consolidação da sociedade competitiva, os mecanismos das trocas políticas tornam-se necessários para a manutenção do poder político e para a ampliação da acumulação de capital amparada em fundos públicos, seja de forma lícita ou ilícita. Isto será prontamente utilizado por setores da sociedade moderna, sobretudo com o avanço do conservadorismo consubstanciado no projeto neoliberal enquanto novo pacto das elites (CARVALHO, 2004).

Nossa história tem sido a realização de interesses de setores localizados com predominância econômica e estratégias de controle sobre nossas dinâmicas políticas limitadas, em especial nos processos eleitorais. Essa realidade também é marcada por momentos de grande força das ruas e movimentos de mobilização em massa que conformam as políticas públicas, a exemplo da campanha das diretas já de 1984 e da Constituição de 1988. Ainda assim, as cenas contemporâneas também indicam que as próprias massas podem ser manipuladas em função de interesses alheios aos seus próprios.

Com histórico de frágil e oscilante democracia, a sociedade brasileira segue marcada por personagens com fortes bases locais destacando-se e influenciando o cenário político mais abrangente, em geral, carregando o prestígio do sobrenome das famílias tradicionais conhecidas nas pequenas cidades pelas benfeitorias à população local. Eles podem se deslocar por diferentes estruturas partidárias e assimilar novos métodos de fazer política, mas conseguiram manter sua força política no âmbito local ou mesmo irradiá-la para outras esferas do poder.

A legitimação de um grupo familiar na política de uma região não se restringe à tradição familiar. Em combinação com o prestígio do sobrenome, a legitimidade que é revertida em votos se alimenta de métodos de coerção e convencimento, incluso as relações de troca de favores, herança da história brasileira. Como já mencionado, a possibilidade de posto de trabalho na esfera municipal, sobretudo em regiões com fraca economia, tornam os eleitores reféns de grupos com maior dominância, criando-se ciclo repetitivo de dependência política e pessoal.

\section{A persistência da herança familiar na política contemporânea}

A persistência de herança familiar na política é uma das dimensões limitadoras da cidadania política por estabelecer condições diferenciadas na disputa de votos. Uma das evidências é que jovens e inexperientes candidatos, quando oriundos de famílias com trajetórias consolidadas no poder, entram nas campanhas referendados por capital político que lhes permitem ascender ao parlamento de modo precoce. Isto ocorre a despeito de suas capacidades e de caminhada política própria. Elegem-se com base em votos herdados de modo natural pelo pertencimento à família, bem como a partir das relações políticas construídas anteriormente e pelo suporte de poder que o exercício em cargos políticos assegura.

Em balanço realizado sobre os congressistas eleitos em 2010 pela ONG Transparência Brasil podemos ter ideia do impacto da tradição familiar nos processos eleitorais mais recentes quando vemos entre os deputados federais a significativa presença de jovens herdeiros.

O resultado mostra que as relações de sangue podem ser importante capital político: na Câmara e no Senado, quase metade dos congressistas alavancaram parentes ou foram por eles promovidos; entre os deputados federais com menos de 30 anos, o número de 'herdeiros' chega a quase 80\%. (SCHOENSTER, 2014a, p. 1).

O estudo indica que jovens com menos de 40 anos e no primeiro cargo eletivo compunham $70 \%$ da Câmara de Deputados naquele mandato. Quando o estudo focou na faixa etária de menos de 30 o percentual 
subiu para $78 \%$. Além desse perfil de jovens herdeiros políticos, o impacto dos laços parentais é mais acentuado entre as mulheres, frequência de 58\% na Câmara e no Senado chega a 91\% (SCHOENSTER, 2014a).

Considerando as regiões de origem dos deputados, verifica-se que os do Nordeste que tem ou tiveram parentes com carreira política representam $60 \%$ do total da bancada, sendo que os da região Sul estão em menor número: $34 \%$. No Senado, por sua vez, a bancada do Nordeste é composta por $70 \%$ de herdeiros políticos, enquanto as demais regiões variam entre 50\% a 67\%. Portanto, de modo geral, parcela significativa de congressistas conta com forte apoio da tradição familiar para alcançar um mandato também.

Do ponto de vista da filiação partidária, o PFL/DEM tem $67 \%$ de seus deputados eleitos em consonância com a tradição de suas famílias e o PMDB, segunda maior bancada do período, também tinha percentual significativo: $64 \%$ do total de deputados. Já a maior bancada, a do PT, aparece com o menor percentual: $17 \%$. Por sua vez, o PSDB com a terceira maior bancada tinha $43 \%$ de seus membros da Câmara seguindo a tradição familiar, mas no Senado esse percentual sobe para $82 \%$ e o PMDB fica com $78 \%$ do seu conjunto. Portanto, os partidos com perfil ideológico conservador apresentam fortemente a característica da herança política familiar, mas esta tendência também já aparece em outros com perfil progressista como o PT.

Em continuidade a esse levantamento, a Transparência Brasil fez nova análise a partir das eleições de 2014 (SCHOENSTER, 2014b) e o resultado não apenas indica a continuidade da presença de herdeiros políticos no Congresso, mas chega a evidenciar número maior do que na legislatura anterior no caso de deputados federais: $49 \%$ desses têm famílias com políticos que os antecederam ou exercem mandatos concomitantes, sendo cinco pontos a mais que no período anterior. No Senado, houve uma redução de quatro pontos comparativamente à legislatura anterior, mas a representatividade continua alta: $60 \%$ dos senadores têm parentes na política. Quanto às mulheres, o novo estudo apresenta alto índice de deputadas (55\%) e senadoras (60\%) com parentes na política. No caso dos estados a situação é também muito evidente:

A única mulher eleita governadora entre as 27 unidades federativas foi Suely Campos (PP-RR), casada com o ex-deputado federal Neudo Campos (PP-RR). Suely protocolou sua candidatura após a renúncia do marido, impedido de concorrer pela Lei da Ficha Limpa. Ademais [...] todas as sete vice-governadoras eleitas têm parentes políticos. (SCHOENSTER, 2014b, p. 2).

A força da tradição familiar nas instâncias políticas se revela também em outro estudo da Transparência Brasil a partir de levantamento de conselheiros dos tribunais de contas de todo o Brasil:

Foram encontradas relações de parentesco com políticos para $32 \%$ dos conselheiros. As relações são
diversas e demonstram, em alguns casos, laços com figuras influentes na política local há diversas gera-
ções. Em um caso, o poder remonta ao período imperial: o clã político cearense Paula Pessoa, ao qual
pertence o conselheiro Luís Alexandre Albuquerque Figueiredo de Paula Pessoa, do TCE-CE, conta com
oito gerações de políticos influentes. O conselheiro, além de ter pai, irmão e sobrinho na política subnacional,
tem como antepassado um senador do Império. (PAIVA; SAKAI, 2016, p. 9).

De modo geral, esses estudos da organização Transparência Brasil são importantíssimos para que possamos compor um quadro geral do impacto da influência familiar na política em várias instâncias do poder. Entretanto, esses dados também requerem certa reserva na medida em que, exatamente por tratar-se de estudos gerais, podem sugerir uma relação direta entre o parentesco e laços políticos em sintonia ou mesmo como herança política.

A Transparência Brasil trabalha com o foco no que considera "[...] oligarcas e seus filhos, netos, cônjuges, irmãos e sobrinhos [...]" (SCHOENSTER, 2014b, p. 1) e tem como pressuposta a relação direta de herança familiar para a inserção e continuidade na política. Entretanto, se focarmos o estudo partindo para análises mais pessoais, podemos encontrar casos em que não necessariamente o vínculo com a política é decorrência do parentesco ou relação de matrimônio. Isto é comprovado em duas situações apresentadas nesses estudos.

Em primeiro lugar, trata-se da vice-governadora do Ceará, Izolda Cela (mandato 2015-2018), que vem de militância em movimento estudantil. Na ocasião estabeleceu fortes relações políticas com os irmãos Ferreira Gomes em Sobral, assim como o seu posterior companheiro e ex-prefeito daquela cidade, Veveu Arruda. Talvez a continuidade na política deva-se muito mais às relações políticas e pessoais com o clã Ferreira Gomes do que consequência matrimonial com o então prefeito de Sobral. Isto é mais evidente ao se considerar que tanto um como outro exerceram cargos administrativos na gestão municipal de Sobral quando Cid Gomes era prefeito e a própria Isolda continuou atuando nos dois mandatos de Cid no governo do Ceará. Isto sugere que o apoio do referido clã ocorreu tanto para a eleição de Veveu na prefeitura de Sobral (2013-2016) como a escolha de Isolda para a chapa que sucedeu Cid Gomes no governo do Ceará no posto de vice-governadora. 
Em segundo lugar, encontramos a situação da atual deputada federal Luizianne Lins (mandato 20152018) e que aparece na contagem de deputadas com parentesco em virtude de ser "[...] ex-mulher de Sérgio Novais (PSB-CE), primeiro suplente do senador José Pimentel (PT-CE) e ex-deputado federal" (SCHOENSTER, 2014b, p. 10). Independente da relação conjugal dos dois parlamentares, Luizianne Lins iniciou carreira política, tal qual Izolda Cela, no movimento estudantil. Com tal inserção política, passagem em Centro Acadêmico da Comunicação Social e Diretório Central dos Estudantes da UFC, foi a vereadora mais votada em Fortaleza em 1996 e reeleita em 2000. Este segundo mandato não foi concluído por ter sido eleita a deputada estadual mais votada no Ceará e a quarta entre todos os deputados do estado (2002). Em seguida concorreu à eleição de prefeita de Fortaleza por dois mandatos consecutivos (2004 e 2008). A carreira meteórica de Luizianne, e o envolvimento posterior com Sérgio Novais, não autoriza qualquer conclusão quanto à influência do ex-marido para a sua eleição como deputada federal, quando ela obteve a $9^{\mathrm{a}}$ colocação na lista dos 22 (vinte e dois) deputados federais eleitos por aquele estado.

Portanto, nos dois casos, a herança política de caráter familiar não tem fundamento, assim como os referidos estudos tomam como pressuposta a relação de gênero de modo equivocado. Isto por considerar a inserção da mulher na política motivada pelo vínculo matrimonial, obscurecendo o protagonismo das eleitas nesse processo. Assim, é recomendável que se pondere sobre a condição das 07 (sete) vice-governadoras que o estudo sugere o êxito eleitoral ao parentesco, especificamente no caso de $71,4 \%$ delas que têm cônjuges na política. Para tanto seria necessária a investigação da trajetória de cada uma, o que não pode ser realizado no estudo aqui proposto. Isto não elimina o impacto de tantas mulheres com parentesco na política seguirem a carreira de seus cônjuges e parentes, mas não pode ser tomado como regra geral.

A despeito dessas ponderações, alguns números impressionam quanto à realidade que envolve as mulheres na política. Esse segmento tem restrita participação política parlamentar, mesmo com grande peso populacional e por representarem $45 \%$ da força de trabalho. Na legislatura 2010-2014 elas ocupavam 9\% das vagas na Câmara Federal, 13\% no Senado e 13\% nas assembleias legislativas (SANTOS; PAIVA, 2014). Nas eleições de 2014, passaram a ocupar 51 (cinquenta e uma) cadeiras, 06 (seis) a mais do que na legislatura anterior, representando $10 \%$ do total, o que não altera substancialmente sua participação (SCHOENSTER, 2014b, p. 2).

Por sua vez, Santos e Paiva $(2014$, p. 2) indicam que as mulheres têm taxa de arrecadação financeira para suas campanhas bem menores que a dos homens. No pleito de 2010, as candidatas à Câmara Federal arrecadaram $68 \%$ a menos do que os homens, sendo que as parlamentares eleitas tiveram arrecadação em torno de $11 \%$ a menos que os eleitos. As deputadas estaduais eleitas também arrecadaram $10 \%$ a menos que seus colegas homens, e as candidatas de modo geral tiveram índice de arrecadação $52 \%$ menor do que os candidatos homens.

As senadoras eleitas no período tiveram que se esforçar em termos de arrecadação para lograrem êxito, quando arrecadam $27 \%$ a mais em média que os senadores eleitos. Em função dos mandatos serem conquistados com esforço maior, Santos e Paiva (2014) sustentam que para as deputadas federais serem eleitas é fundamental o capital político de parentes na política. Estas conseguiram arrecadar quase o dobro das que não têm parentes, embora destaquem não haver essa relação entre as senadoras e deputadas estaduais eleitas.

Deste apanhado dos estudos da organização Transparência Brasil fica evidente que a relação entre política e laços familiares é característica marcante dos processos eleitorais no Brasil. Outros estudos apontam para as mesmas conclusões sobre o peso político da família para se chegar a um mandato parlamentar.

\footnotetext{
[...] discussão ilustra um mecanismo muito antigo da política nacional e especialmente significativo na atual legislatura na Câmara. De teor fortemente conservador, ela é também a que possui maior porcentual de deputados familiares políticos desde as eleições de 2002. Um estudo da Universidade de Brasília (UnB) publicado no segundo semestre de 2015 analisou os 983 deputados federais eleitos entre 2002 e 2010 para concluir que, no período, houve um crescimento de 10,7 pontos percentuais no número de deputados herdeiros de famílias de políticos, atingindo 46,6\% em 2010 - número próximo aos $44 \%$ encontrados pela Transparência Brasil no mesmo ano. Logo após a última disputa eleitoral, a ONG divulgou outro levantamento que concluiu que 49\% dos deputados federais eleitos em 2014 tinham pais, avôs, mães, primos ou cônjuges com atuação política - o maior índice das quatro últimas eleições. (MEDEIROS, 2016).
}

Ainda se tratando da relação mulher e política, quando se verifica o vínculo familiar como suposto para a ascensão a cargos públicos, pode-se constatar um efeito danoso do ponto de vista da administração de políticas sociais. Neste caso, há reprodução do papel de primeiras damas como a condutoras naturais da assistência social. 
Em 1987, foi fundado no Ceará, com a participação de 17 primeiras-damas, a Associação das Primeiras Damas dos Municípios do Ceará, posteriormente designada de Associação para o Desenvolvimento dos Municípios do Ceará-APDMCE. [...] das 11 presidentas: 3 já foram deputadas estaduais, 3 vereadoras, 1 senadora, 02 ex Secretárias Municipais da Saúde, 02 ex Gestoras do Fundo Municipal de Assistência Social, 01 ex Secretária de Ação Social, 01 ex Secretária da Indústria e Comércio, 01 ex Secretária de Cultura, 01 ex prefeita, 03 viceprefeitas. Nesse balanço, encontram-se pessoas que exerceram mais de uma função no decorrer dos anos. [...] É relevante também termos identificado na diretoria do Colegiado Estadual de Gestores Municipais de Assistência Social - COEGEMAS, no biênio 2011/2012, a presença de 4 primeiras-damas, sendo que dentre estas estavam 2 ex secretárias de Ação Social em um total de 3 mandatos, 1 vereadora com 2 mandatos. No biênio 2013/2014, encontramos 2 primeiras-damas, sendo 2 ex secretárias de Assistência Social, uma destas eleita 5 vezes vereadora e com 3 mandatos como secretária de Assistência Social. (LOPES et al., 2013, p. 7-8).

Desse conjunto de dados é possível inferir que a influência administrativa das primeiras damas não se descola do mandato de seus maridos/companheiros, independente de suas capacidades técnicas e políticas. Ao mesmo tempo, essa atribuição como gestora da assistência reproduz a histórica relação dessa política com a prática da filantropia, mesmo com marcos legais estabelecidos a partir da criação da Lei Orgânica da Assistência Social - LOAS. Corre-se o risco de que a execução de referida política possa estar associada também à permanência de elementos da prática política tradicional, quer dizer, a manutenção das estratégias de troca de favores e o clientelismo como instrumentos que dão suporte e constituem a história política brasileira.

De modo geral, essas pesquisas identificam a força do personalismo e da tradição familiar como elementos decisivos para as vitórias eleitorais, decorrendo daí a importância também do controle político do poder local para as eleições de deputados federais e estaduais. Nesse sentido, é intensa a influência familiar na escolha de candidatos em diversos níveis, preferencialmente no interior do clã político ou em articulação com suas bases partidárias que podem extrapolar a relação familiar, mas não deixa de passar por essa cadeia de relações e de apoios políticos.

\section{Considerações finais}

O Brasil tem histórico de democracia tardia e oscilante, com ciclos longos de processos ditatoriais e instituições políticas frágeis. Com esse histórico de autoritarismo, a sociedade brasileira não conseguiu alcançar o patamar devido da cidadania burguesa, e sequer preservar de forma mais ou menos igualitária as liberdades e os direitos de todos. Em consequência, a disputa pelo poder continua ancorada no domínio patrimonialista da elite política e econômica. Isto é predominante nos momentos eleitorais, mas se estende ao exercício do poder político em geral. Nas duas situações prevalece a realização de interesses egoístas e predatórios com o fundo público.

A Constituição de 1988 viabilizou conquistas democráticas e estabeleceu patamares mais amplos de exercício de direitos e acesso a bens e políticas sociais. Entretanto, a disputa em termos de projeto de país continua travada por pensamento conservador que não admite a igualdade e cidadania burguesas. Tampouco as elites recuaram na perspectiva patrimonialista, e continuam a se apoderar da estrutura burocrática do Estado e do fundo público com fins de realização de seus interesses próprios.

Sem o reconhecimento da possibilidade de cidadania, e tampouco da elite política e econômica abrir mão de usufruto predatório dos recursos do Estado, torna-se inviável o fortalecimento das políticas sociais. Isto não apenas pela incapacidade de socializar os bens públicos, mas porque o pensamento conservador não admite a convivência com iguais.

O Brasil segue inseguro quanto aos rumos da institucionalidade democrática. O golpe que tirou o mandato de Dilma Rousseff conduziu ao poder Michel Temer, um de seus articuladores e beneficiário direto, com a tarefa de realizar contrarreformas que tendem a reduzir direitos sociais e trabalhistas, ampliando a fratura da sociedade. Nessas condições amplia-se a cultura autoritária e senhorial das elites, avançando sobre a estrutura do Estado no sentido de reverter conquistas sociais dos últimos tempos.

Essa realidade já fora potencializada com o quadro de contrarreforma neoliberal em curso desde os anos 1990 e segue com o novo ciclo de poder. A perspectiva é que parte significativa do Estado seja abocanhada pelo capital a partir da privatização de sua estrutura e funções produtivas; há sérios riscos que os custos do trabalho sejam ainda mais relativizados com o crescimento das terceirizações e a flexibilização dos contratos de trabalho; é possível que sejam criados entraves ao acesso às políticas sociais com nova reforma da previdência e a crescente mercantilização da saúde e da educação. Inviabilizava-se, de fato, o próprio conceito universal de cidadania. 
A ideologia neoliberal, sua perspectiva de fortalecimento do mercado e redução da cidadania à dimensão do consumo encontra identidade com a cultura política patrimonialista das elites locais. Esta cultura senhorial (CHAUÍ, 2000) é elemento limitador da perspectiva da própria cidadania burguesa e sua materialização na forma de políticas sociais amplas. Tal cultura se sustenta também no predomínio da herança familiar em diferentes esferas do poder.

\section{Referências}

CARVALHO, A. M. P. Radicalizar a democracia: o desafio da reinvenção da política em tempos de ajuste. Revista de Políticas Públicas, São Luís (MA), EDUFMA, v. 8, n. 2, p. 7-26, 2004. Disponível em: <http://www.periodicoseletronicos.ufma.br/index.php/rppublica/ article/view/3757/1822>. Acesso em: 4 maio 2016.

CHAUÍ, M. O que comemorar? Projeto História, São Paulo, v. 20, p. 35-62, abr. 2000. Disponível em: <https://revistas.pucsp.br/ index.php/revph/article/view/10800/8020>. Acesso em: 4 maio 2016.

FAORO, R. Os donos do poder: formação do patronato político brasileiro. 3. ed. rev. São Paulo: Globo, 2001.

FERNANDES, F. A revolução burguesa no Brasil: ensaio de interpretação sociológica. 5. ed. São Paulo: Globo, 2006.

FREIRE, P. Educação como prática da liberdade. 36. ed. Rio de Janeiro: Paz e Terra, 2014.

LOPES, E. C. et al. As primeiras-damas na política cearense: um estudo das décadas de 1970 à de 2010. In: JORNADA INTERNACIONAL DE POLÍTICAS PÚBLICAS, 6., 2013, São Luís (MA). Anais eletrônicos... São Luís (MA): UFMA, 2013. Disponível em: <http:// www.joinpp.ufma.br/jornadas/joinpp2013/JornadaEixo2013/anais-eixo3-estadolutassociaisepoliticaspublicas/asprimeirasdamasnapoliticacearense-umestudodasdecadasde1970ade2010.pdf $>$. Acesso em: 4 maio 2016.

MARTINS, J. de S. O poder do atraso: ensaios de sociologia da história lenta. São Paulo: Editora Hucitec, 1994.

MEDEIROS, E. Você conhece nossa Câmara dos Deputados? Dinastias familiares ocupam quase metade das cadeiras. Opera Mundi, São Paulo, 30 abr. 2016. Disponível em: <http://operamundi.uol.com.br/conteudo/samuel/44001/ voce + conhece+nossa + camara + dos + deputados + dinastias + familiares + ocupam+quase + metade + das + cadeiras.. html $>$. Acesso em: $31 \mathrm{abr}$. 2016.

PAIVA, N.; SAKAI, J. Quem são os conselheiros dos Tribunais de Contas. Transparência Brasil, São Paulo, abr. 2014. Disponível em: $<$ http://www.atricon.org.br/wp-content/uploads/2014/04/TransparenciaBrasil_TribunaisdeContas_Abril2014.pdf $>$. Acesso em: 4 maio 2016.

SAKAI, J.; PAIVA, N. Quem são os conselheiros dos Tribunais de Contas? Transparência Brasil, São Paulo, 2016. Disponível em: $<$ https://www.transparencia.org.br/downloads/publicacoes/TBrasil\%20-\%20Tribunais\%20de\%20Contas\%202016.pdf>. Acesso em: 4 dez. 2016.

SANTOS, R. A.; PAIVA, N. A presença das mulheres no parlamento brasileiro. Transparência Brasil, São Paulo, jun. 2014. Disponível em: <http://monitoramentocedaw.com.br/wp-content/uploads/2013/08/Mulheres-parlamento.pdf>. Acesso em: 4 maio 2016.

SCHOENSTER, L. Clãs políticos no Congresso Nacional. Transparência Brasil, São Paulo, jun. 2014a. Disponível em: <http:// excelencias.org.br/docs/parentes.pdf>. Acesso em: 4 maio 2016.

Clãs políticos seguem dominando no Congresso na próxima legislatura. Transparência Brasil, São Paulo, nov. 2014b. Disponível em: <http://excelencias.org.br/docs/parentes_\%202015-2018\%20vf.pdf>. Acesso em: 4 maio 2016.

\section{Maria Cristina de Queiroz Nobre}

cristina.nobre@uece.br

Doutora em Sociologia pela Universidade Federal do Ceará (UFC)

Professora do Curso de Serviço Social e Mestrado Acadêmico em Serviço Social, Trabalho e Questão Social da Universidade Estadual do Ceará (UECE)

\section{UECE}

Av. Dr. Silas Munguba, 1700 - Campus do Itaperi

Fortaleza - Ceará - Brasil

CEP: 60.714-903 